\title{
Critical Evaluation of Entrepreneurial Tendency in Engineering Graduates
}

\author{
${ }^{1}$ Dr. Sunita Dhote, ${ }^{2}$ Prof. Satyajit Uparkar, ${ }^{3}$ Prof. Sharad Bhave \\ ${ }^{1,2}$ Assistant Professor, Shri Ramdeobaba College of Engineering and Management, Nagpur \\ ${ }^{3}$ Co-ordinator, Department of Business Management, C P\& Berar E S College, Nagpur \\ Email:dhotesn@rknec.edu,uparkarss@rknec.edu,sdbhave@gmail.com
}

\section{Received: $20^{\text {th }}$ September 2018, Accepted: $11^{\text {th }}$ October 2018, Published: $31^{\text {st }}$ October 2018}

\begin{abstract}
Economic growth always contributes to the overall growth and thereby "the happiness index" of a country. In the Indian context, growth rate, whether 7.5 or 8.5 is the current topic of debate and discussion is politicized beyond limits. However, the fact remains that growth rate depends on the business generated and that in turn is operated by entrepreneurs and intrapreneurs (employees who possess entrepreneurial spirit). An entrepreneur creates wealth and subsequently helps the growth of GDP of a nation (India). In the present context, the mantle of entrepreneurship rests on the youth of today. Keeping this in view, a project was undertaken to investigate and evaluate 'their entrepreneurial skills'. For the sake of study, a small section of the youth, engineering graduates is selected. Three hundred students studying in final year engineering belonging to four groups namely Computer group, E group, Civil engineering and Mechanical engineering are focused on 'the basic characteristics such as need for achievement, need for autonomy, creativity, internal locus of control, risk taking, and general enterprising tendency. This paper attempts to identify the extent of entrepreneurial talent among the budding engineers. The ultimate aim is to forecast a number of engineering graduates turning into first generation entrepreneurs.
\end{abstract}

\section{Keywords}

Entrepreneurial Tendency, Need for Achievement, Need for Autonomy, Creativity, Risk Taking, Internal Locus of Control, General Enterprising Tendency

\section{Introduction}

Start-ups and entrepreneurs as a necessity of any economy to increase in the Gross Domestic Product to make the economy developed one. The current external environment is rapidly changing be it political or technical or legal or environmental. Today's generation in this given volatile environment has to choose for their professional career options, which is at times very confusing. Thus, entrepreneurship is solution to the innovative career option, as it is disruptive in nature. It can lead to enterprise venture of so many permutations and combinations.

It is very important for every student to develop these tendencies, whether they have to open their own business or as a government employee or wants to do a social service or want to work as an employee in the private sector or for any technical sector. So it is very important for the educations institute at large to inculcate these 5 entrepreneurial tendencies in the student, so that they have a successful career in future.

Consequentially it is a challenge to enforce entrepreneurial tendency amongst the technical students. As students appearing for technical education are with different personalities and mindsets or are bought up in different sets of background, thus different students may develop their entrepreneurial tendencies in various manners. Therefore, this paper has a goal to study the entrepreneurial features of selected different engineering discipline.

\section{Literature Review}

According to (Solow and Swan, 1956) economic growth of an economy depends on the production function, which consider labour and capital invested in the given more number of enterprises is an essential cause for development of an economy. As these firms encourages self-employment opportunities, skilled labour and investment in economy. According to (Schumpeter J., 1934) entrepreneurs introduces creativity and innovation in the economy by developing new types of business models. Most of the countries unemployment is a major economic problem and solution to it is self-employment, which calls for enhancing entrepreneurial skills in youth (Wang \& Wong, 2004). World today is facing ample number of challenges with respect to youth like unemployment, drugs, health, crime at early age, hunger, waste of times and resources. (Kasim et al. 2014), (Geldhofet al. 2014), (Commission, 2012). Youth today is facing problem of lack of knowledge, lack of entrepreneurial skills, non-capital investments, not aware of government incentives and tax holidays. (Brixiov, Ncube, \&Bicaba, 2015). 


\section{Research Problem}

On the basis of above mention problem statement we have formulated the following research question

- Technical graduation education enhances the entrepreneurial tendencies i.e. need for achievement, need for autonomy, calculated risk-taking, internal locus of control and a creative tendency.

- The study has been conduct 2017-18 batch of engineering students, wherein the research is on the entrepreneurial tendency of Technocrats.

\section{Research Design}

Today there is need to enhance the entrepreneurial tendency amongst the graduate technocrats in India, in order to positively contribute to gross domestic product of Indian economy, thus this study aims to identify to intensity Indian technical education contributes to enhances the entrepreneurial tendency

\section{The Objective of Study}

To study the access of the entrepreneurial tendency of Computer group, Electronics group, Civil engineering and Mechanical engineering students.

\section{Scope of Study}

The data used primary data. The General Enterprising Tendency Test was developed in 1987-1988 by Dr Sally Caird and Mr Cliff Johnson at Durham University Business School (Caird, Sally (1990)), has been administered amongst the 300 final year students of Bachelor of Engineering of Mechanical, Electronics group, Civil and Computer groups. Electronics group of the E Group includes students from Electrical Engineering, Electronics Engineering, Electronics and Telecommunication and also Electronics and Design. On the other hand Computer Group has students from Computer Science and Engineering along with Information Technology.

\section{Pilot Survey and Reliability Test}

To identify the reliability of the model a pilot survey using an initial sample of 30 engineering students was conducted. Cronbach's Alpha values based on the total scores of all 9 rows and the 6 characteristics are given in the following table.

\begin{tabular}{|c|c|c|c|c|c|}
\hline Sr. No. & Index & $\begin{array}{c}\text { No. of } \\
\text { items }\end{array}$ & $\begin{array}{c}\text { Initial } \\
\text { Sample size }\end{array}$ & $\begin{array}{c}\text { Cronbach's } \\
\text { Alpha value }\end{array}$ & Inference \\
\hline 1 & Scores of each rows & 9 & 30 & 0.762 & Acceptable \\
\hline 2 & Scores of each characteristics & 6 & 30 & 0.776 & Acceptable \\
\hline
\end{tabular}

\section{Table 1: Reliability Test for Pilot Survey}

Inference: Since both the Cronbach alpha values lies between $0.7-0.8$, the questionnaire is fairly acceptable for this research work. The model is reliable to conduct the survey for the remaining samples. The sample distribution of the four groups is given in the following figure.

\section{5\% Details of Sample Distribution}

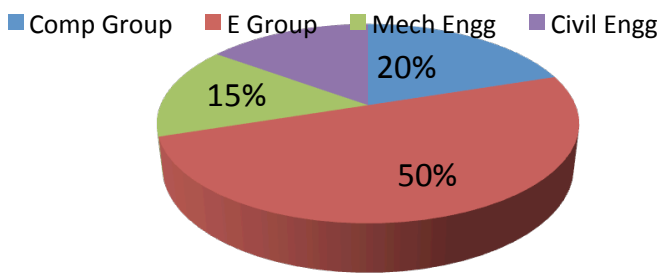

Fig. 1: Sample Distribution

Inference: Since E Group includes 150 samples from Electrical Engineering, Electronics Engineering, Electronics and Telecommunication and also Electronics and Design which ultimately reflects $50 \%$ of the sample distribution. Computer Group includes 60 samples from only two Engineering branches i.e. Computer Science and Engineering 
along with Information Technology, which contributes $20 \%$ of the sample distribution. Lastly the Civil Engineering Branch and Mechanical engineering branch contributes individually with 45 samples each, which makes $15 \%$ each of the sample distribution.

\section{Data Analysis}

By the proper use of a standard GET2test Answer and Scoring Sheet, where 54 questions arranged in 9 different rows, the data for each of the items was entered in the Excel sheet. The mapping criterion for various levels is given in the following table.

\begin{tabular}{|c|c|c|c|c|c|c|}
\hline Levels $\rightarrow$ & \multicolumn{2}{|c|}{ Low Level } & \multicolumn{2}{c|}{ Medium Level } & \multicolumn{2}{c|}{ High Level } \\
\hline Limits $\rightarrow$ & Min (>=) & $\operatorname{Max}(<)$ & Min (>=) & $\operatorname{Max}(<)$ & Min (>=) & Max (<) \\
\hline Need for autonomy & 0 & 3 & 3 & 4 & 4 & 6 \\
\hline $\begin{array}{c}\text { For other 5 Individual } \\
\text { Characteristic }\end{array}$ & 0 & 7 & 7 & 10 & 10 & 12 \\
\hline $\begin{array}{c}\text { General Enterprise } \\
\text { Tendency }\end{array}$ & 0 & 27 & 27 & 44 & 44 & 54 \\
\hline
\end{tabular}

Table 2: Criterion for Mapping of various Levels

Note: For need for autonomy, only Row No. 3 has been considered. Every other characteristic is the total of respective two rows. Lastly for General Enterprise Tendency the total scores of all the 9 rows have been considered. On the basis of the above mapping, following table provides the proportion of percentage for each of the characteristics, at three different levels for the four Engineering groups. This table reflects the tendency of students' perception towards each of the characteristics for becoming future Entrepreneurs.

\begin{tabular}{|c|c|c|c|c|c|}
\hline Characteristics & $\begin{array}{c}\text { Branches } \rightarrow \\
\text { Levels } \downarrow\end{array}$ & $\begin{array}{l}\text { Comp. Group } \\
\text { (60 Samples) }\end{array}$ & $\begin{array}{c}\text { E Group } \\
\text { (150 Samples) }\end{array}$ & $\begin{array}{l}\text { Mech. Engg. } \\
\text { (45 Samples) }\end{array}$ & $\begin{array}{l}\text { Civil Engg. } \\
\text { (45 Samples) }\end{array}$ \\
\hline \multirow{3}{*}{$\begin{array}{c}\text { Need for } \\
\text { achievement }\end{array}$} & Low & $0 \%$ & $20 \%$ & $22 \%$ & $11 \%$ \\
\hline & Medium & $67 \%$ & $57 \%$ & $45 \%$ & $56 \%$ \\
\hline & High & $33 \%$ & $23 \%$ & $33 \%$ & $33 \%$ \\
\hline \multirow{3}{*}{$\begin{array}{l}\text { Need for } \\
\text { autonomy }\end{array}$} & Low & $17 \%$ & $30 \%$ & $11 \%$ & $22 \%$ \\
\hline & Medium & $25 \%$ & $23 \%$ & $11 \%$ & $22 \%$ \\
\hline & High & $58 \%$ & $47 \%$ & $78 \%$ & $56 \%$ \\
\hline \multirow{3}{*}{$\begin{array}{l}\text { Creativity } \\
\text { tendency }\end{array}$} & Low & $17 \%$ & $27 \%$ & $44 \%$ & $22 \%$ \\
\hline & Medium & $50 \%$ & $50 \%$ & $44 \%$ & $56 \%$ \\
\hline & High & $33 \%$ & $23 \%$ & $12 \%$ & $22 \%$ \\
\hline \multirow{3}{*}{$\begin{array}{l}\text { Calculated } \\
\text { risk taking }\end{array}$} & Low & $25 \%$ & $23 \%$ & $22 \%$ & $44 \%$ \\
\hline & Medium & $42 \%$ & $54 \%$ & $67 \%$ & $44 \%$ \\
\hline & High & $33 \%$ & $23 \%$ & $11 \%$ & $12 \%$ \\
\hline \multirow{3}{*}{$\begin{array}{l}\text { Internal locus of } \\
\text { control }\end{array}$} & Low & $8 \%$ & $33 \%$ & $33 \%$ & $33 \%$ \\
\hline & Medium & $84 \%$ & $47 \%$ & $45 \%$ & $33 \%$ \\
\hline & High & $8 \%$ & $20 \%$ & $22 \%$ & $34 \%$ \\
\hline \multirow{3}{*}{$\begin{array}{c}\text { General } \\
\text { Enterprising } \\
\text { Tendency }\end{array}$} & Low & $0 \%$ & $13 \%$ & $22 \%$ & $11 \%$ \\
\hline & Medium & $75 \%$ & $74 \%$ & $67 \%$ & $78 \%$ \\
\hline & High & $25 \%$ & $13 \%$ & $11 \%$ & $11 \%$ \\
\hline
\end{tabular}

Table 3: Branch Wise Statistics for Various Characteristics

Inference: In case of the "Need for autonomy", students of all engineering branches were found Maximum at High level. This indicates that every engineering student thinks to be

- Independence, preferring to work alone especially if he cannot be top dog.

- Self-expressive, feeling a strongly need to do their own thing accordingly in their way, rather than work on other people's projects.

- Individualistic and unresponsive to group pressure.

- Leadership, preferring to be in charge and disliking taking orders.

- Unconventional, and prepared to stand out as being different to others. 
- Opinionated, having to say what they think and make up their own mind about issues.

- Determination, strong willed and stubborn about their own interests.

Students from Computer group showed nil responses at low level, for the characteristics of "Need for achievement" as well as for "General Enterprising Tendency". This indicates that the students of Computer Group are-

- Charged to become future entrepreneurs,

- Seek opportunities and use resources to achieve their plans,

- In a belief, that they possess or can gain the qualities to be successful,

- Innovative and willing to take a calculated risk to achieve their goals successfully,

Except for Need for autonomy, all the other characteristics maps maximum at Medium level. This indicates that engineering students are likely to have strengths in some of the enterprising characteristics and may be enterprising in some contexts. As an engineering graduate, they probably are unlikely to set up an innovative growth-oriented global business, and may be able to express their enterprise either within employment as an entrepreneur, or in their leisure time through voluntary community projects.

So it can be seen that, a technically sound student, in general aspire to have their own enterprise or enjoys working in freedom with responsibilities.

\section{Descriptive Statistics}

The central tendency and the dispersion within the data help to find out the general trend. The ratio of Standard deviation and the Average value indicates the consistency among the student perception towards becoming the entrepreneurs. Following table provides the consistency levels for each of the characteristics among each of the Engineering groups.

\begin{tabular}{|c|c|c|c|c|c|}
\hline Characteristics & Branches & Average & Std. Dev. & $\begin{array}{c}\text { Coeff. of } \\
\text { Variation }\end{array}$ & $\begin{array}{c}\text { Consistent by } \\
\text { Ranking }\end{array}$ \\
\hline \multirow{4}{*}{$\begin{array}{l}\text { Need for } \\
\text { achievement }\end{array}$} & Comp. Group & 8.92 & 1.57 & $18 \%$ & $1 *$ \\
\hline & E Group & 7.73 & 1.78 & $23 \%$ & 2 \\
\hline & Mech. Engg. & 8.33 & 2.34 & $28 \%$ & 4 \\
\hline & Civil Engg. & 8.11 & 2.05 & $25 \%$ & 3 \\
\hline \multirow{4}{*}{ Need for autonomy } & Comp. Group & 3.75 & 1.17 & $31 \%$ & 3 \\
\hline & E Group & 3.4 & 1.55 & $45 \%$ & 4 \\
\hline & Mech. Engg. & 4.44 & 1.27 & $29 \%$ & 2 \\
\hline & Civil Engg. & 3.44 & 0.97 & $28 \%$ & $1 *$ \\
\hline \multirow{4}{*}{ Creativity tendency } & Comp. Group & 8.92 & 1.86 & $21 \%$ & $1 *$ \\
\hline & E Group & 7.97 & 1.95 & $24 \%$ & 2 \\
\hline & Mech. Engg. & 7 & 1.97 & $28 \%$ & 3 \\
\hline & Civil Engg. & 7.78 & 2.23 & $29 \%$ & 4 \\
\hline \multirow{4}{*}{$\begin{array}{l}\text { Calculated } \\
\text { risk taking }\end{array}$} & Comp. Group & 8.67 & 2.11 & $24 \%$ & 2 \\
\hline & E Group & 7.73 & 1.99 & $26 \%$ & 3 \\
\hline & Mech. Engg. & 7.56 & 1.52 & $20 \%$ & $1 *$ \\
\hline & Civil Engg. & 7.22 & 1.95 & $27 \%$ & 4 \\
\hline \multirow{4}{*}{$\begin{array}{l}\text { Internal locus of } \\
\text { control }\end{array}$} & Comp. Group & 8.33 & 1.12 & $13 \%$ & $1 *$ \\
\hline & E Group & 7.17 & 2.32 & $32 \%$ & 3 \\
\hline & Mech. Engg. & 7.56 & 2.29 & $30 \%$ & 2 \\
\hline & Civil Engg. & 7.44 & 2.39 & $32 \%$ & 3 \\
\hline \multirow{4}{*}{$\begin{array}{c}\text { General } \\
\text { Enterprising } \\
\text { Tendency }\end{array}$} & Comp. Group & 38.58 & 4.84 & $13 \%$ & $1 *$ \\
\hline & E Group & 34 & 6.59 & $19 \%$ & 2 \\
\hline & Mech. Engg. & 34.89 & 6.95 & $20 \%$ & 3 \\
\hline & Civil Engg. & 34 & 7.20 & $21 \%$ & 4 \\
\hline
\end{tabular}

Table 4: Branch Wise Descriptive Statistics for Various Characteristics

Inference: It can be noticed that, all the corresponding average values tends towards the High level of perception against all of the characteristics for becoming the future Entrepreneurs. According to the last column, Computer Students are consistent with respect to (i) Need for achievement, (ii) Creativity Tendency, (iii) Internal locus of 
control and (iv) General Enterprising Tendency. This indicates that computer science engineering involves the students in more and more field based project.

On the other hand Civil Engineering students seem to be consistent with respect to need for autonomy. This indicates that most of the civil engineering students want to do their work independently, they can be an Intrapreneur. It can also been seen that these students have shown more variation in other factors. This means that Civil engineering Students has influence of other parameters like.

Lastly Mechanical Engineering students have shown their consistency in calculated risk taking factor. Electronics Group reflects least consistency in need for autonomy, while they stand second or third in every other characteristic under consideration. This indicates that these students are not at present self-motivated,

\section{Inferential Statistics}

The purpose of inferential statistics is to estimate that the samples under consideration are good enough to support the fact for the entire population. The data analysis of this research work is based on the scores of the various characteristics obtain against the samples of four different groups. The objective is to identify the presence of significant difference between these four groups on the basis of each characteristic under consideration. Hence, on the basis of the final scores obtained from the four different groups, 6 different hypothetical statements are framed against each of the characteristics under consideration. For decision, the level of significance is considered at $\alpha=5 \%$. So any $\mathrm{p}$ value calculated from $\mathrm{F}$ statistics is more than or equal to 0.05 will accept the null hypothesis for the characteristic under consideration. In case if any $\mathrm{p}$ value calculated from $\mathrm{F}$ statistics is less than 0.05 will reject the null hypothesis and we can accept the respective alternative hypothesis for the characteristic under consideration.

For this, one way Analysis of Variance is the best tool. Use of SPSS is made to carry out this test.

Generalized Hypothetical Statement-

$\mathrm{H}_{0 \mathrm{n}}$ : There is no significance difference between the four engineering groups with respect to $\mathrm{n}^{\text {th }}$ characteristic under consideration.

vs

$\mathrm{H}_{1 \mathrm{n}}$ : There is some significance difference between the four engineering groups with respect to ${ }^{\text {th }}$ characteristic under consideration.

(Note: Here $\mathrm{n}=1$ stands for "Need for achievement", $\mathrm{n}=2$ stands for "Need for autonomy", $\mathrm{n}=3$ stands for "Creativity tendency", $n=4$ stands for "Calculated risk taking", $n=5$ stands for "Internal locus of control" and $n=6$ stands for "General Enterprise Tendency".)

The following table shows the calculation of F statistics, its $p$ value and its inference for each the hypothetical statement.

\begin{tabular}{|c|c|c|c|c|}
\hline Value of n & Characteristic & F statistics & p value & Inference \\
\hline 1 & Need for achievement & 5.944 & .001 & Reject $\mathrm{H}_{01}$ \\
\hline 2 & Need for autonomy & 7.218 & .000 & Reject $\mathrm{H}_{02}$ \\
\hline 3 & Creativity tendency & 8.332 & .000 & Reject $\mathrm{H}_{03}$ \\
\hline 4 & Calculated risk taking & 5.574 & .001 & Reject $\mathrm{H}_{04}$ \\
\hline 5 & Internal locus of control & 4.263 & .006 & Reject $\mathrm{H}_{05}$ \\
\hline 6 & General Enterprise Tendency & 7.775 & .000 & Reject $\mathrm{H}_{06}$ \\
\hline
\end{tabular}

Table 5: Summary of Hypothesis Testing

\section{Conclusion}

It can been seen that at 5\% level of significance, we can reject all the null hypothetical statements against all the 6 characteristics under consideration and accept all alternatives hypothetical statements to consider the fact that there is some significant difference between the four engineering groups with respect to each of the characteristics under consideration. This indicates that the tendency towards the characteristics of all the engineering students belonging to the four different groups does not stand identical. Every group seems to have its own perception towards becoming the future Entrepreneur.

\section{Suggestions}

Computer group Students are consistent with respect overall general enterprising tendency. This indicates that computer students are more inclined towards design, development an analysis of software as well as the hardware for solving the social problems may be business related one. 
On the other hand Civil Engineering students seem to be consistent with respect to need for autonomy. This indicates that most of the civil engineering students want to do their work independently, as they are developing their skills regarding design and building of infrastructure projects, which calls for independent working without any one interference. Mechanical Engineering students have shown their consistency in calculated risk taking factor as they are in developing their knowledge of analysis and interpretation of given situation. Electronics Group reflects least consistency in need for autonomy, while they stand second or third in every other characteristic under consideration. This indicates that these students are mostly reserved by nature as they are trying to develop expertise in the electronic system, which calls for more field based project education. Thus the objective of technical education should be to develop the expertise of the given areas as well as to entrepreneurial skills like selfmotivation, financial responsibility, to recognize and seize the diversified opportunities present in the external environment.

\section{References}

[1] BJERKE, B. 2013. About Entrepreneurship. Cheltenham: Edward Elgar Publishing.

[2] CAIRD, S. 1990. What Does it Mean to be Enterprising? British Journal of Management, 1(3): $137-145$.

[3] CAIRD, S. 1991. Testing Enterprising Tendency in Occupational Groups. British Journal of Management, 2(4): $177-186$.

[4] CAIRD, S. 1993. What do psychological tests suggest about entrepreneurs? Journal of Managerial Psychology, 8(6): 11-20.

[5] FLEŠKOVÁ, M. and BABJAKOVA, B. 2011. Entrepreneurship in relation to Big Five personality dimensions [in Slovak: Podnikanievovzt’ahu k osobnostnýmdimenziám Big Five]. In: Sociálneprocesy a osobnost' 2010: zborníkpríspevkov. StaráLesná, 20-22 September. Košice: Spoločenskovednýústav SAV, 100-107.

[6] GARTNER, W. B. 1988. Who is an Entrepreneur? is the wrong question. American Journal of Small Business, 12(4): 11-32.

[7] HAYEK, F. 1941. The Pure Theory of Capital. Chicago: University Press.

[8] HOLIENKA, M. et al. 2013. Role of family entrepreneurial role models in determining students' preferences towards entrepreneurship. In: Proceedings of ICERI2013 Conference. IATED, Seville, Spain, 18-20 November. IATED, 3722- 3730 .

[9] IAC. 2006. Youth entrepreneurship: theory, practice and field development. A Background Paper Prepared for the W. K. Kellog Foundation.

[10] KNIGHT, F. H. 1921, Risk, Uncertainty and Profi t. Hart, Schaff ner, and Marx Prize Essays, No. 31. Boston and New York: Houghton Miffl in.

[11] KOH, H. C. 1996. Testing hypotheses of entrepreneurial characteristics: a study of Hong Kong MBA students. Journal of Managerial Psychology, 11(3): 12-25. 